\title{
Knowing Communication Strategy for Better Communication
}

\author{
${ }^{1}$ Rona Merita, ${ }^{2}$ Sony Eko Adisaputro \\ ${ }^{12}$ IAI Pangeran Diponegoro Nganjuk \\ ${ }^{1}$ ronamerita@iaipd-nganjuk.ac.id, ${ }^{2}$ sonynganjuk07@gmail.com
}

\begin{abstract}
Nowadays, the importance of communication is undeniable. In oral communication, the learners employ speaking skills which requires the mastery of communication strategies in order to solve the communication problems which they found during oral communication and to get across the communicative goals to the interlocutors. Unfortunately, speaking is still considered one of the most difficult skills to be acquired by English language learners. English learners need more practices and also strategies in communication. In addition, communication ability also influenced by some factors such as target language proficiency, learning and communicating contexts, task types, gender differences and learners' personality. Driven by this condition, this paper is aimed to discuss theoretical framework about communication strategies and its development since firstly proposed by Tarone (1977). This paper is beneficial for English language practitioner and English language learners, ELT researcher as well.
\end{abstract}

Keywords: communication strategies, theoretical, framework

\section{INTRODUCTION}

The prominent role of English for global communication affects the aim of learning English. Previously, English was learned to access information written in English. In respect to this aim, learning English was focused on developing the reading skill. However, nowadays, in order to fulfill the demand of global communication, learning English is aimed at developing effective communication. Doing communication, people can send and receive messages effectively and negotiate the meaning (Rubin \& Thompson, 1994: 30). Consequently, most language learners focus their study on communication ability, especially speaking skill. As Richards and Renandya (2002: 201) stated that "A large percentage of the world's language learners study English in order to develop proficiency in speaking”. In addition, the importance of speaking also reported by Yani (2007:43) in her publication which points out that in this era how to communicate effectively in foreign language learning becomes much more important than reading and writing.

Furthermore, in order to be able to create effective communication, language learners need to acquire communicative competence. Communicative competence is the concept that is developed under the views of language as context, language is interaction, and language is negotiation (Widiati \& Cahyono, 
2006: 273). Thus, learning to communicate using English requires more than the grammatical and seman- tic rule. According to Canale and Swain (1980), communicative competence is comprised of grammatical competence, discourse competence sociolinguistic competence, and strategic competence. For the lasts, the component is that strategic competence is considered as the most im-portant of all communicative competence com- ponents (Shumin, 2002: 208). Strategies competence is defined as "verbal and nonverbal strategies that may be called into action to compen- sate for breakdowns in communication due to performance variable or insufficient competence" (Fauziati, 2009: 168). Dealing with face to face communication, strategic competence refers to an ability to know when and how to take the floor, how to keep a conversation going, how to terminate the conversation, and how to clear up communication breakdowns as well as comprehension problems.

In the literature, strategic competence involves learning strategy and communication strategy, yet this paper only deliberately discusses communication strategy. In the EFL context, language learners commonly experience some problems in a face-to-face conversation using English. In generals, these problems occurdue to lack of vocabulary and knowledge of English. Thus, communication strategy plays animportant role to facilitate learners in manipulating or modifying their language in order to meet communicative goals.

Driven by the explanation above, the aimsof this paper are giving overview toward the definition of Communication Strategies, theoretical review toward kinds of Communication Strategies proposed by previous expert, criteria of Communication Strategies, tactic for analyzing learners communication strategies, and affected factor in applying Communication Strategies. Furthermore, theoretically this paper provide fully understanding for readers about the development of communication strategies.

\section{MATERIAL AND METHODS \\ Defining Communication Strategy}

Along with the increasing number of studies on communication strategy, there are various definitions of communication strategy available in the literature. Selinker (1977) is a first scholar who postulates the term of communicative strategies or strategies in second language communication to refer to one of the process that responsible for producing interlanguage error. Moreover, he defines communicative strategy asan identifiable approach by the learner to com- municate with native speakers of the target lan-guage (1977: 37). In addition, Tarone (1981 in Fauziati, 2010) explains communication strategies as a systematic attempt by the learner to express and decode meanings in the target lan-guage in situations where the appropriate systematic target language used has not been formed. Communicative strategies, therefore, serve to compensate for the inadequacies of speakers and listeners in the target language, which is being used. 
After examining his definition of communication strategies, he revises it to make it clear. The notion of the communication strategy is broadened beyond the learner's attempt to use a restricted linguistic system for communication. Since the fact that both speaker and hearer create communication, a joint negotiation meaning of anagreement on meaning can occur during doing conversation. As a result, the term communication strategy relates to "a mutual attempt of two interlocutors to agree on meaning in situations where requisite meaning structures do not seem to be shared". Due to the focus of this definitionis on the interaction process, this definition of communication strategy known as an interaction- al definition. In conclusion, the interactional function of CSS can be as an attempt to bridgethe gap between the linguistic knowledge of tar- get language, and the linguistic knowledge of the target language interlocutor in real communication situations.

Instead of an interactional definition, there are other definitions which are against the previous definition. These definitions recognized as a psycholinguistic definition. They are Faerch and Kasper (1983), Corder (1983). Faerch and Kasper (1983) define CSS as a potentially conscious plan for solving what an individual presents itself as a problem in reaching a particular communicative goal. Here, CSS is seen as a part of the planning process. CSS is employed when learners experience some problem with their ini- tial plan so that they decide to avoid executing their plan or they develop an alternative plan by making use of achievement strategies. Corder (1978 in Faerch and Kasper 1983) stated that CSS is a systematic technique employed by a speaker to express his meaning when faced with some difficulty.

\section{Understanding Existing Taxonomies of Communication Strategy}

Likewise have a definition of communication strategy, there are various taxonomies of communication strategy exist. Applied linguistic scholars who are interested in studying communication strategy seem competing for their taxonomy. Considering to diversity of existing taxonomies, (Fauziati, 2010) argues that these classifications reflect more or less the same categorization. Furthermore, this part presents some taxonomies of acommunication strategy proposed by Tarone(1981), Dornyei (1995), CelcieMurcia et.al (1995), and Dornyei and Scott (1997).

Tarone (1981) classified communication strategy into seven strategies as follows: (1) topic avoidance; (2) Message Abandonment; (3) the use of paraphrase; (4) Coinage (creating new words); (5) native language switching; (6) mim- ing (the use of non-linguistic resources), and (7) appeal for assistance. Meanwhile, Dornyei (1995) divides communication strategy into thirteen strategies that classified into avoidance strategies and compensatory strategies. Avoidance

strategies include (1) message abandonment and (2) topic avoidance. Compensatorystrategies covers (1) circumlocution; (2) approximation; (3) use of all 
purposed word; (4) word coinage; (5) prefabricated pattern; (6) nonlinguistic signals; (7) literal translation; (8) foreignizing; (9) code-switching; (10) Appeal for help; and (11) stalling or time-gaining.

In addition, Celce-Murcia and her col- leagues classify communication strategies into five types, they are (1) avoidance or reduction strategies; (2) achievement or compensatory strategies; (3) stalling or time gaining strategies; (4) self-monitoring strategies; and (5) interactional strategies. Avoidance or reduction strategies include message replacement, topic avoidance, and message abandonment. The achievement or compensatory strategies cover circumlocution, approximation, all purposed words, non-linguistic means, restructuring, word coinage, a literal translation from L1, foreignizing, code-switching, and retrieval. Stalling or time- gaining strategies include fillers, hesitation de- vices, and gambits. Self-monitoring strategies entail self-initiated repair and self rephrasing. The last, interactional strategies involve appeals for help, meaning negotiation, responses, andcomprehension checks.

In responding to the availability of various taxonomies of communication strategies in which many scholars seem competing for their taxonomy, Dornyei and Scott (1997) summarize some existing taxonomies based on problems of communication: (1) own-performance problem; Other performance problem, and (3) processing time pressure. As a result, they notice taxonomy of communication strategy consisting of direct strategies, interactional strategies, and indirect strategies. Direct strategies cover resource deficit related strategies (message abandonment, message reduction, message replacement, circumlocution, approximation, use of all purposes words, word coinage, restructuring literal translation, foreignizing, code switching, use of similar sound words, mumbling, omission, retrieval, mime), own performance problem related strategies (selfrephrasing and self-repair), other performance problem related. Meanwhile, interaction strategies involve resource deficit related strategies (appeal for help), own-performance problem related strategies (comprehension check, and own accuracy check), other-performance problem related strategies (asking for repetition, asking for clarification, asking for confirmation, guessing, expressing nonunderstanding, interpretative summary, and responses), and the last subcategory is indirect strategies which include processing time pressure related strategies (use of fillers and repetitions), own performance problem related strategies (verbal strategy markers), and other performance problem related strategies (feigning understanding).

In addition, Widiarini (2016) found another communication strategies employed by English learners when they meet problems in accomplish-ing their communicative tasks. These strategies does not exist in Dornyei and Kormos's Taxonomy (1998), they are mime (nonlinguistic/ paralinguistic strategies) and use of similar phrasal verb. Mime is Describing whole concepts non-verbally or 
accompanying a verbal strategy with a visual illustration. Similar phrasal verb means phrasal verb that has similar base verb. These are similar phrasal verb used by English learners during accomplishing communicativetask: 'look for' for 'look at'; 'far away' for 'stay away'; and 'oversleep' for 'fall asleep'.

\section{Criteria of Communication Strategy}

Communication using target language which is conducted by language learners is always becomes an interesting phenomenon to be investigated. Moreover, in order to investigate CSS employed by learners, some criteria should be considered. A review of the CSs literature notices that there are two defining criteria should be mentioned to study CSs, problem orientedness, and consciousness.

Problem orientedness criterion is fully influenced by the original insight of CSs in which it has been assumed as a strategy used to overcome the communication problem caused by the gap between communicative intention and linguistic resources. Along with the broader concept of CSs, Dornyei, and Scott (1997: 183) extended communication problem into three types in which they only restricted on recourse deficit. Furthermore, the three types of communication problem as well: (1) Own performance problems: the realization that something one has said is incorrect or only partly correct; associated with various types of selfrepair, self -rephrasing and self-editing mechanisms; (2) Others performance problems: something perceived as problematic in the interlocutor's speech, either because it is thought to be incorrect (or highly unexpected), or because of alack (or uncertainty) of understanding some- thing fully; associated with various meaning negotiation strategies; (3) Processing time pres- sure: the L2 speakers' frequent need for more time to process and plan L2 speech that would be naturally available in fluent communication; associated with strategies such as of fillers, hesi-tation devices, and self-repetition.

Moreover, consciousness criterion of CSs was related to the CSs definition postulated by Faerch and Kasper (1983). They define CSs as potentially conscious plans for solving what an individual presents itself as a problem in reaching a particular communicative goal. It means that as a conscious strategy, CSs is used to achieve a communication goal. Dornyei and Scott (1997) propose consciousness of CSs involve: (1) Consciousness as awareness of the problem: it only covers language processing problem that the speaker consciously recognizes should be as CSs in order to distinguish mistake and CSs that may have a similar erroneous form; (2) Consciousness as intentionality: it deals with the speaker intentional use of the CSsseparate CSs from certain verbal behaviors that are systematically related to the problems of which the speaker is aware but that are not doneintentionally; (3) Consciousness as awareness of strategic language use: the speaker realizes that 
he/she is using less than perfect, stopgap device or is doing a problem-related way to mutual meaning. This differentiates CSs from cases when intentionally doing something to overcome a recognized problem, the speaker may not consider the final product of strategy but rather a piece of acceptable L2.

Based on the explanation above, it can be seen that the learners are indicated utilizing CSs only when they experience the language problem and they realize that they face the problem and then they utilize strategies to solve the problem for achieving their communication goal. Furthermore, Tarone (1981 in Færch and Kasper, 1983) proposed the following criteria that are characterized as CSs in a simple way. It reflects the process of how communication breakdown solved. It covers three criteria: (1) A speaker desires to communicate a meaning $\mathrm{X}$ to a listener; (2) The speaker believes that linguistic or sociolinguistic structure desired to communicate meaning $\mathrm{X}$ is unavailable or is notshared with the listener; (3) The speaker chooses to: avoid no attempt to communicate meaning $X$; or attempt alternate means to communicate meaning $\mathrm{X}$ (the speaker stops trying alternatives when it seems clear to the speaker that there is shared meaning). From those criteria of CSs, it reveals that in order to identify CSs the terms problemorientedness and consciousness should be an indicator of the phenomena in which the students employed CSs.

\section{Analyzing Learners' Communication Strategies}

Analyzing learners' communication strategies can be begun by looking at how learners alternate or modify their utterance in communication. Various alternative devices have been proposed (Tarone, 1981; Dornyei, 1995; CelceMurcia et.al, 1995; and Dornyei and Scott, 1997).To do this analysis, the researcher should gather learners' language used in a communicative task. Diversity of tasks have been operated by scholars to collect communication strategies phenomenon. Varadi who first examined learners' communication strategies employed a picture story description task. In addition, Tarone and Swierzbin (2009) use question or interview task, Jigsaw, and retell task to get the data of learners' language. Furthermore, other communicative activities can be conducted to collect the real language produced by learners. During the learners are doing an activity, records the activity by using audio or video recording is required for further analysis. After learners' language has been collected, the researcher transcribes the audio or video recording, later on, this activity followed by classifying the communication strategies into the existing taxonomy. In this case, the researcherneeds to select one of the taxonomies to classify the data.

Moreover, when a researcher is eager to analyze communication strategies employed by a large number of learners, the questionnaire is required. To do this, the researcher can use a questionnaire that has been developed by Nakatani(2006). This questionnaire called the Oral Communication Strategy Inventory (OCSI). It 
covers 59 questions which classified into (1) social affective strategies; (2) fluency-oriented strategies; (3) negotiation for meaning while speaking; (4) accuracy-oriented strategies; (5) message reduction and alternation strategies; (6) nonverbal strategies while speaking; (7) message abandonment strategies; (8) attempt to think in English strategies; (9) negotiation for meaning while listening; (10) fluency maintaining strategies; (11) scanning strategies; (12) getting the gist strategies; (13) nonverbal strategies while listening; (14) less active listener strategies; and (15) word oriented strategies.

\section{RESULTS AND DISCUSSION}

\section{The Role of Communication Strategy in L2 Acquisition}

Various studies of CSs reveal more understanding of the effect of CSs on the development of L2 acquisition. Kasper and Kellerman (in Ellis, 2008) identified a number of ways in which CSs may assist L2 acquisition, CSs:

(1) Help to keep the flow of the conversation going and thus increase learners " expose toinput.

(2) Trigger negotiation for meaning which aidacquisition.

(3) Increase their control over their existing linguistic sources.

(4) Enables learners to obtain access to new linguistic resources through the corporate strategic solution.

(5) Fill gaps in the learners ${ }^{\text {ee }}$ lexicon through positive feedback following a request for assistance.

(6) Produce pushed output.

(7) Increase overall processing control.

In accordance with the role of CSs in communication, Saputra (2014) also reported that learners to reduce harmful anxiety in communication utilized CSs. Oxford (1999) in Fauziati (2010) explains harmful anxiety as a negative factor that influences second language acquisition.It is related to nervousness or tension that rids learner from accomplishing the comunicative task. In this case, CSS is employed by learners to eliminate nervousness during speak using L2. Furthermore, Abdullah (2011: 116) argues that knowing and practicing CSS will encourage students " confidence to speak and interact in the various communicative occasion. It is supported by the fact that CSS can be utilized as alternative devices to convey a meaning that may be caused by a lack of knowledge in L2. From the discussion above, in sum the roles of CSS cover facilitating learners to communicate and negotiate their intended meaning to achieve the communicative goal and reducing effective factors which affect communication successfulness. 


\section{Factors Affecting the Use of Communication Strategy}

Along with the development of studies on communication strategies, some factors influencing the choices of communication strategies have existed in the literature. Some factors that have been investigated include:

1. Target language proficiency. Jidong (2011) argues that L2 learners employ CSS due to their interlanguage systems are still developing and insufficient. Some studies have reported that among high-proficiency learners and low proficiency learners employdifferent communication strategies.

2. Learning and communicating contexts. Ellis in Jidong (2011) argues that learners " use of communication strategies is affected by the situation of use. For example, Lafford (2004) (cited in Jidong, 2011: 93) examined the use of CSS by learners of Spanish whois studying at home (University of Colorado) and learners who are studying abroad in Spain. The results indicated that both the study at home and at abroad learners reduced their reliance on CS use over time and study abroad learners used fewer CSS that at home learners.

3. Task types. It is possible that learners employed different communication strategies when they perform the task. The reason is task-related factors such as the purpose of each task, the formality of the communication situation, the cognitive complexity of the task and the status of interlocutors may greatly and have unequal effects on the interlocutors.

4. Gender differences. Some studies of communication strategies have indicated that gender is one of the important variables which effects both frequency and type of CSS employed by learners. Catalan (2003) and Wang Limei (2008) (cited in Jidong, 2011) proposed the reason of this phenomenon is that females hold more positive attitudes and stronger motivations towards language learning and culture so that they tend to achieve higher marks.

5. Learners" personality. Based on learners "personality, the learner can be divided into twotypes; they are extrovert and introvert learners. In general, extrovert learners seem moreinteractive in communication than the introvert one (Jidong, 2011). In order to keep theircommunication runs smoothly, they commonly use more interactive strategies in communication.

\section{CONCLUSION}

The comprehensive and voluminous literature about communication strategies has been inhand. From all of the overview, it can be summarized that communication strategy is beneficial for managing communication. Having knowledge of communication strategies and then employing them in communication, benefits to encounter communication problems that may occur dueto own performance problem, other performance problem, and time pressuring as communication is an interactive process in which speaker and hearer involved 
actively in the process. Furthermore, regarding the importance of communication strategies, these can be included in teaching English, especially in speaking. In addition, as Indonesian learners are a non-native speaker of English, all English learners in Indonesia commonly face a gap of knowledge of English so how they can over- come communication problem is very importantto be investigated.

\section{REFERENCES}

Abdullah, U. (2011). EIL in Practice: Indonesia and Chinese International Postgraduate Students Negotiate meaning. TEFLIN, 2 (22), 103-124.

Celce-Muria, M., Dornyei, Z., \& Thurrell, S. (1995). A Pedagogical Framework for Communicative Competence: A Pedagogically Motivated Model with Content Specifications. Issues in Applied Linguistics. 6(2), 5-35.

Corder, S. P. (1983). Strategies of Communication. In: Færch, C. \& Kasper, G. (Ed). Strategies in Interlanguage Communication. New York: Longman.

Dornyei, Z. \& Scott, M.L. (1997). Communication Strategies in a Second Language: Definitions and Taxonomies. Language Learning, 47(1), 173210.

Dornyei, Z. (1995). On the Teachability of Communication Strategies. TESOL Quarterly, 29, 55-85.

Ellis, R. (2008). The Study of Second LanguageAcquisition. Oxford: Oxford University Press.

Færch, C. \& Kasper, G (1983). On Identifying Communication Strategies in Interlanguage Production. In: Færch, C. \& Kasper, G. (Ed). Strategies in Interlanguage Communication. New York:Longman.

Færch, C. \& Kasper, G. (1983). Strategies in Interlanguage Communication. New York: Longman.

Fauziati, E. (2009). Reading on Applied Linguistics: A Handbook for Language Teacher and Teacher Researcher. Surakarta: PT. Era Pustaka Utama.

Fauziati, E. (2010). Teaching English as a Foreign Language. Surakarta: Era Pustaka Utama.

Jidong, G. (2011). Empirical Studies on L2 Communication Strategies over Four Decades: Looking Back and Ahead.Chinese Journalof Applied Linguistics. 34 (4), 89-106.

Nakatani, Y. (2006). Developing an oral Communication Strategy Inventory. The Modern Language Journal, 90 (ii), 151-168.

Richards, J.C., \& Renandya, W. A. (Eds.). (2002). Methodology in Language Teaching: An Anthology of Current Practice.New York: Cambridge University Press.

Rubin, J. \& Thompson, I. (1994). How to Be a More Successful Language Learner. New York: Heinle \& Heinle. 
Saputra, Krisna I. (2014). Communication Strategies Employed by Students in the English Study Program of University PGRI Ronggolawe Tuban. Unpublished Thesis of University of Sebelas Maret Surakarta.

Shumin, K. (2002). Factors to Consider: Developing Adult EFL Students" Speaking Abilities.

In Richards, J.C., \& Renandya,

W. A. (Eds.). (2002). Methodology in Language Teaching: An Anthology of Current Practice. New York: Cambridge University Press.

Tarone, E. \& Swierzbin, B. (2009). Exploring Learner Language. Oxford: Oxford University Press.

Tarone, E. (1983). Some Thoughts on the Notion of Communication Strategy. In: Færch,

C. \& Kasper, G. (Ed). Strategies in Interlanguage Communication. New York: Longman.

Widiarini. (2016). Communication Strategies Used By English Learners at Basic English Course (BEC) Pare Kediri. Masters Thesis, Universitas Sebelas Maret.

Widiati, U. \& Cahyono, B.Y. (2006) The Teaching of EFL Speaking in the Indonesia Context: The State of the Art. BAHASA DAN SENI, 34 (2), 269-291.

Ya-ni, Z. (2007). Communication Strategies and Foreign Language Learning. USChina Foreign Language, 5(43), 43-47 